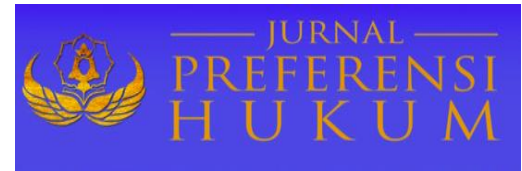

\title{
TANGGUNG JAWAB PELAKU USAHA TERHADAP KONSUMEN GO FOOD DALAM TRANSAKSI E-COMMERCE
}

\author{
I Putu Wisna Dana, Ni Luh Made Mahendrawati, Ni Gusti Ketut Sri Astiti \\ Fakultas Hukum Universitas Warmadewa, Denpasar-Bali, Indonesia
}

\begin{abstract}
Abstrak
Transaksi ekonomi kini telah dipadukan dengan teknologi internet yang sering disebut e-commerce. Meskipun telah diatur sedemikian rupa untuk melindungi hak-hak konsumen, namun penggunaan perjanjian baku dalam transaksi e-commerce tetap memiliki resiko kerugian besar pada pihak konsumen. Berdasarkan latar belakang masalah yang telah diuraikan tersebut diatas, maka penelitian ini dilakukan dengan tujuan menguraikan tanggung jawab pelaku usaha terhadap konsumen jika terjadi wanprestasi dalam transasksi Go Food mempergunakan $e$ commerce dan menggambarkan sanksi bagi pelaku usaha Go Food yang berlaku curang dalam mempergunakan e-commerce. Mengacu pada perumusan masalah, maka penelitian ini didesain dengan menggunakan pendekatan penelitian normatif. Metode yang digunakan dalam pengolahan bahan hukum, yaitu metode analisis data deksriptif analitis. Sesuai dengan hasil analisis data, tanggung jawab pelaku usaha terhadap wanprestasi dalam transasksi Go Food yang menggunakan $e$-commerce adalah melakukan pengembalian saldo Go-Pay. Sanksi bagi pelaku usaha Go Food yang berlaku curang dalam mempergunakan e-commerce, yang mengakibatkan kerugian pada konsumen, tidak hanya terbatas pada pemberhentian mitra saja, tetapi sanksi juga dapat diberikan pada pelaku usaha yang tidak bertanggung jawab. Sanksi yang dimaksud dapat berupa sanksi perdata, pidana ataupun administrasi.
\end{abstract}

Kata Kunci: Konsumen; Perlindungan Hukum; Transaksi E-commerce.

\begin{abstract}
Economic transactions have been integrated with internet technology which is often called e-commerce. Although it has been arranged in such a way to protect the rights of consumers, the use of standard agreements in ecommerce transactions still has the risk of large losses to consumers. Based on the background of the problems above, this research was conducted with the aim of elaborating the responsibilities of business actors to consumers in the event of default in the Go Food transaction using e-commerce and describing sanctions for Go Food businesses that apply fraudulent use of e-commerce. Referring to the formulation of the problem, this study was designed using a normative research approach. The method used in the processing of legal materials, namely analytical descriptive data analysis methods. In accordance with the results of data analysis, the responsibility of business operators for defaults in Go Food transactions using e-commerce was to return Go-Pay balances. Sanctions for Go Food businesses that apply cheating in using e-commerce, which result in losses to consumers, were not only limited to the dismissal of partners, but sanctions could also be imposed on irresponsible business actors. The sanctions in question could be in the form of civil, criminal or administrative sanctions.
\end{abstract}

Keywords: Consumers; Legal Protection; E-commerce Transactions.

\section{PENDAHULUAN}

Keberadaan internet memberikan dampak yang besar bagi perkembangan kehidupan manusia saat ini (Mahmood, 2016). Munculnya internet memberikan manfaat yang luar biasa pada sendi-sendi kehidupan manusia, yang mana salah satunya adalah dengan mempercepat dan mempermudah pekerjaan manusia itu sendiri (Eko, 2001). Selain mempermudah pekerjaan manusia, manfaat lain dari adanya internet adalah memberikan sarana untuk berkomunikasi, dapat dimanfaatkan untuk penyebaran dan pencarian informasi, bisa mempermudah siswa untuk belajar dengan mempergunakan e-book secara daring (online), dan yang saat ini sedang berkembang pesat adalah penggunaan internet untuk 
pengembangan bisnis online yang tentunya sangat menguntungkan semua pihak, dengan penyerapan tenaga kerja yang banyak dan pendapatan yang luar biasa bagi negara.

Transaksi ekonomi kini telah di padukan dengan teknologi internet yang kemudian sering di sebut e-commerce (Imammulhadi, 2002; Nogoev, Yazdanifard, Mohseni, Samadi, \& Menon, 2011). Namun dengan adanya manfaat tersebut, ada pula sisi lainnnya yang berdampak negatif, yakni masih adanya praktik-praktik transaksi yang dilakukan dengan e-commerce yang melakukan kecurangan sehingga merugikan konsumen itu sendiri, dan menimbulkan permasalahan-permasalahan hukum berkaitan dengan e-commerce (Suparni, 2001).

Berkaitan dengan masalah hukum hal tersebut adalah mengenai perlindungan hak-hak konsumen yang terdesak dengan pemberlakuan e-commerce yang berkaitan dengan jual-beli barang dan/atau jasa baik di dalam negeri atau pun di luar negeri sendiri (Acheampong et al., 2017; Mancuso, 2007). Kecurangan yang sering terjadi dalam jual-beli e-commerce dapat melibatkan perusahaan yang menjual jasa dan/atau barang, barang yang dijualnya, bahkan proses transaksi online yang dilakukan. Hal inilah yang merugikan konsumen. Mekanisme transaksi yang dilakukan dengan e-commerce sebenarnya sama dengan mekanisme transaksi yang dilakukan secara konvensional. Namun perbedaannya dapat dilihat dengan transaksi e-commerce dilakukan dengan menggunakan komputer atau laptop, bahkan smartphone dan tentunya harus dikoneksikan dengan internet. Dalam transaksinya pula terdapat perjanjian elektronik atau dikenal juga dengan kontrak elektronik (Makarim, 2000; Romadhoni \& Kharisma, 2019). Penggunaan kontrak elektronik dalam transaksi e-commerce tidak semata-mata berbeda unsurnya dengan kontrak konvensional. Hal ini diatur secara khusus dan diuraikan dalam ketentuan Pasal 48 ayat (3) Peraturan Pemerintah Nomor 82 Tahun 2012 Tentang Penyelenggaraaan Sistem dan Transaksi Elektronik.

Melihat ketentuan dalam Pasal 18 UU Perlindungan Konsumen yang mana disebutkan tujuan perlindungan konsumen adalah untuk melindungi hak-hak konsumen dalam perjanjian baku yang dibuat oleh pelaku usaha, dan dalam perjanjian baku ini konsumen selalu berada dalam posisi yang lemah dibandingkan dengan pelaku usaha. Namun, pengaturan tersebut memberikan celah bagi pelaku usaha yang nakal untuk berbuat curang yang merugikan konsumen terutama dalam pelaksanaan perjanjian baku dalam transaksi e-commerce. Adanya perjanjian baku dalam sebuah transaksi e-commerce akan mempersempit ruang tawar konsumen (Abib, Kridasaksana, \& Nuswanto, 2015). Perjanjian baku juga memberikan sebuah persyaratan yang dirumuskan secara sepihak oleh pihak yang lebih kuat, dimana pihak yang lebih kuat ini biasanya adalah pelaku usaha.

Berkaitan dengan latar belakang masalah yang telah diuraikan di atas, maka rumusan masalah penelitian ini difokuskan pada pendeskripsian tanggung jawab pelaku usaha terhadap konsumen jika terjadi wanprestasi dalam transasksi Go Food yang menggunakan e-commerce dan penguraian sanksi bagi pelaku usaha Go Food yang berlaku curang dalam mempergunakan e-commerce?

\section{METODE PENELITIAN}

Mengacu pada perumusan masalah, pendekatan penelitian yang digunakan adalah pendekatan penelitian hukum normatif. Penelitian hukum normatif didasarkan pada penelitian kepustakaan atau dengan menggunakan bahan hukum sekunder lainnya (Mamudji, 1995). Sumber data penelitian ini terdiri dari bahan hukum primer yang diperoleh dari perundang-undangan, catatan resmi atau risalah dalam pembuatan perundang-undangan dan putusan-putusan hakim yang telah mendapatkan keputusan hukum tetap. Sumber data kedua adalah bahan hukum sekunder. Data dikumpulkan dari referensi buku teks, bahan hukum lainnya yang di dalamnya mengandung pandangan-pandangan hukum para yuris. Penggunaan bahan hukum sekunder dalam penelitian ini mempergunakan buku dan jurnal hukum serta lain sebagainya yang berkaitan dengan isu hukum yang diteliti (Sedarmayanti \& Hidayat, 2002). Sumber data yang lain adalah bahan hukum tersier. Dalam penelitian ini bahan hukum tersier yang dipergunakan yaitu Kamus Besar Bahasa Indonesia, Kamus Hukum dan media lainnya yang berkaitan dengan isu hukum yang diteliti. Dalam mengumpulkan data, teknik yang digunakan adalah teknik studi dokumen yang dilakukan dengan membuat catatan terhadap sumber bahan hukum primer dan bahan hukum sekunder, teknik studi kepustakaan yang dilakukan dengan menelaah catatan, buku yang berkaitan dan isu hukum yang akan diteliti, dan teknik studi internet yang dilakukan dengan mengumpulkan bahan atau data yang dicari berkaitan dengan isu hukum di internet. Metode analisis yang digunakan adalah metode analisis deskriptif yang memberikan gambaran komprehensif dan sistematis tentang isu hukum yang diteliti. 


\section{HASIL DAN PEMBAHASAN}

\section{TanggungJawab Pelaku Usaha terhadap Konsumen jika Terjadi Wanprestasi Dalam Transasksi Go Food Mempergunakan E-commerce}

Perkembangan dunia global saat ini terus saja berkembang tanpa ada batasan, bahkan teknologiteknologi baru yang berkaitan dengan sendi-sendi kehidupan manusia modern banyak bermunculan. Teknologi adalah suatu hal yang tidak mungkin terlepas dari kehidupan manusia saat ini (Ngafifi, 2014). Hal tersebut telah menyatu dengan keseharian manusia itu sendiri, dari bangun tidur, beraktivitas, sampai dengan kembali beristirahat. Teknologi adalah pendukung keberlangsungan kehidupan manusia. Salah satu teknologi yang saat ini menjadi candu bagi setiap manusia adalah keberadaan internet yang memiliki manfaat tak terbatas dan mendukung segala aktivitas manusia.

Saat ini internet dipergunakan dalam berbagai bidang, salah satunya adalah aktivitas bisnis yang mendukung efisiensi penjualan atau pemasaran barang atau jasa (Yuliana, 2000). Efisiensi yang dimaksud adalah keuntungan dalam transaksi melalui media internet karena penghematan waktu, baik karena tidak perlunya penjual dan pembeli bertemu secara langsung, mapun tidak adanya kendala transportasi. Selain itu manfaat e-commerce bagi konsumen adalah konsumen tidak perlu meninggalkan rumah untuk mengecek atau membandingkan suatu produk, namun bisa langsung dalam genggaman smartphone, hanya dengan 1 alat (Fauzia, 2016).

Pelaksanaan e-commerce ini juga mencangkup distribusi, penjualan, marketing, pembelian dan servise dari produk yang dilaksanakan dengan metode daring (Wibowo, 2016). Dalam hal ini jasa pembelian dan pengiriman makanan melalui Go Food juga merupakan bentuk dari e-commerce.

Berdasarkan definisi e-commerce di atas, dapat disimpulkan bahwa $e$-commerce merupakan proses transaksi jual beli produk maupun jasa, pertukaran informasi dan pelayanan secara online melalui jaringan internet. E-commerce terbagi atas dua segmen yaitu business to business e-commerce (perdagangan antar pelaku usaha) dan business to consumer e-commerce (perdagangan antar pelaku usaha dengan konsumen) (Atmojo, 2002).

Perusahaan daring (online) Go Jek di Indonesia adalah salah satu penyedia jasa transportasi online yang mempelopori revolusi dalam bidang teknologi internet terapan dalam mempermudah kehidupan manusia. Sedangkan Go Food merupakan salah satu dari pelayanan yang dimiliki Go Jek yang berkaitan dengan jasa pembelian, pengantaran bahan makanan dan/atau minuman yang dilakukan melalui aplikasi khusus Go Jek.

Pada pelaksanaan jasa transportasi yang berbasis online, apabila terdapat suatu hal yang berkaitan dengan tanggung jawab terhadap barang yang diantarkan tidak sesuai dengan pesanan konsumen, maka yang bertanggungjawab adalah pengemudi online (driver) Go Jek tersebut. Ketentuan tersebut telah diuraikan pihak perusahaan Go Jek dalam kebijakannya, contohnya dalam syarat dan ketentuan layanan yang terdapat pada website PT. Go Jek, di poin 5 mengenai “Tanggung Jawab Kami”.

Pertanggungjawaban yang dilakukan oleh PT. Go Jek Indonesia apabila ditemukan adanya wanprestasi terhadap transaksi e-commerce pada jasa pelayanan Go Food yang mana hal tersebut dilakukan oleh pengendara (driver) Go Jek dengan sengaja atau pun tidak sengaja, adalah dilakukan pengembalian saldo atau dana yang telah dibayarkan sebelumnya melalui Saldo Go-Pay sesuai dengan nominal yang dikeluarkan oleh konsumen. Sebagai pelaku usaha, PT. Go Jek Indonesia memiliki kewajiban untuk memberikan ganti rugi atas kerugian konsumen yang timbul karena menggunakan jasanya tersebut.

Kontrak elektronik yang dilakukan antara konsumen dan pelaku usaha dalam hal ini Go Jek tertuang dalam jenis perjanjian baku. Tujuan klausula baku adalah untuk efisiensi waktu dan biaya, namun tidak berarti kontrak baku tersebut mengesampingkan ketentuan Pasal 1338 KUHPerdata, yang merupakan suatu dasar untuk melakukan perjanjian. Dalam transaksi e-commerce, prinsip tanggung jawab mutlak adalah prinsip yang berlaku dalam hal terjadinya wanprestasi. Posisi konsumen yang lemah dalam kontrak baku yang dibuat secara elektronik dalam transaksi Go Food menjadikan tanggung jawab sepenuhnya berada pada perusahaan, yakni Go Jek. Apabila perusahaan tidak bertanggungjawab dalam wanprestasi pada transaksi e-commerce, maka konsumen dapat saja melakukan penuntutan sesuai dengan Pasal 38 dan pasal 39 UU ITE.

\section{Sanksi bagi Pelaku Usaha Go Food yang Berlaku Curang dalam Mempergunakan E-commerce}


Banyaknya muncul kejahatan dalam bidang e-commerce harus ditanggulangi dengan tepat karena berkaitan dengan basis teknologi yang tentunya berbeda dengan jenis kejahatan konvensional selama ini. Indonesia harus mengantisipasi lebih berkembangnya kejahatan teknologi ini dengan sebuah payung hukum yang mempunyai suatu kepastian hukum (Ahmad M Ramli, 2004:61). Jasa pelayanan pengiriman makanan dengan menggunakan Go Food merupakan sub bagian dari pelayanan yang diberikan oleh perusahaan Go Jek Indonesia saat ini. Pelayanan Go Food saat ini menjadi pemasukan terbesar bagi perusahaan Go Jek Indonesia dan juga terlaris dalam pemesanannya. Namun bukan berarti dengan nama besar Go Jek tidak terdapat kekurangan dalam pelayanan yang diberikan. Dalam beberapa hal kecurangan masih saja ditemukan dalam jasa Go Food saat ini.

Berbagai macam bentuk kecurangan yang dilakukan dalam transaksi jasa Go Food antara lain adalah dalam pengiriman makanan atau minuman yang dipesan konsumen serta kecurangan yang terjadi dengan transaksi yang dilakukan dengan uang elektronik melalui Go-Pay yang bisa saja secara tiba-tiba terpotong tanpa sepengetahuan dari konsumen tersebut.

Mengenai sanksi bagi pengemudi (driver) Go Jek yang diketahui melakukan perbuatan curang dalam memberikan pelayanan jasa kepada konsumen pada saat pengiriman makanan atau minuman dalam Go Food sehingga menimbulkan kerugian bagi konsumen adalah dengan pengenaan sanksi berupa penghentian mitra kerja dari PT. Go Jek Indonesia, dan apabila diketahui dalam perbuatannya tersebut adanya unsur pelanggaran atau kejahatan hukum lainnya, maka dapat dikenakan sanksi berupa sanksi pidana, perdata atau administrasi sesuai ketentuan peraturan perundang-undangan yang berlaku.

\section{SIMPULAN DAN SARAN}

\section{Simpulan}

Berdasarkan hasil analisis data yang telah diuraikan diatas, dapat dibuat beberapa simpulan, yaitu: pertama, PT. Go jek bertanggung jawab penuh apabila terjadi wanprestasi dalam transasksi Go Food yang menggunakan e-commerce. Saldo atau dana yang telah dibayarkan sebelumnya dikembalikan kepada konsumen melalui saldo Go-Pay sesuai dengan nominal yang telah dikeluarkan. Ketentuan tersebut telah diuraikan pihak perusahaan Go Jek dalam kebijakannya. Kedua, para pelaku usaha Go Food yang berlaku curang akan dikenakan sanksi. Pengenaan sanksi berupa penghentian mitra kerja dari PT. Go Jek Indonesia, dan apabila diketahui dalam perbuatannya tersebut adanya unsur pelanggaran atau kejahatan hukum lainnya dapat dikenakan sanksi berupa sanksi pidana, perdata atau administrasi sesuai ketentuan peraturan perundang-undangan yang berlaku.

\section{Saran}

Selain hasil dan simpulan yang telah dipaparkan di atas, ada beberapa saran yang perlu disampaikan kepada beberapa pihak terkait yang berkenaan dengan penelitian ini, yaitu: pertama, pemerintah sebaiknya memberikan pengaturan tegas mengenai perlindungan hukum bagi konsumen atau pengguna jasa e-commerce terutama berkaitan dengan kejelasan pertanggungjawaban antara pengendara transportasi online (mitra) dan perusahaan transportasi online. Kedua, masyarakat sebagai konsumen sebaiknya bersikap lebih hati-hati apabila mempergunakan aplikasi yang berkaitan dengan transaksi $e$ commerce agar tidak mudah dijebak atau dicurangi, dengan selalu mengedepankan prinsip kehati-hatian selama bertransaksi $e$-commerce.

\section{DAFTAR PUSTAKA}

Abib, A. S., Kridasaksana, D., \& Nuswanto, A. H. (2015). Penerapan Klausula Baku Dalam Melindungi Konsumen Pada Perjanjian Jual Beli Melalui E-commerce. Jurnal Dinamika Sosial Budaya, 17(1), 122. https://doi.org/10.26623/jdsb.v17i1.508

Acheampong, P., Zhiwen, L., Yeboah-boateng, E. O., Antwi, H. A., Akai, A., \& Otoo, A. (2017). Consumer Rights Protection in Electronic-Commerce in Ghana: Lessons from British Commercial Jurisprudence. 5(2). Retrieved from https://www.researchgate.net/publication/325270346_Consumer_Rights_Protection_in_Electron ic-Commerce_in_Ghana_Lessons_from_British_Commercial_Jurisprudence

Atmojo, P. P. D. (2002). Internet Untuk Bisnis I. Jogjakarta: Dirkomnet Training.

Eko, I. R. (2001). E-commerce: Kiat dan Strategi Bisnis di Dunia Maya. Jakarta: T. Elex Media Komputindo.

Fauzia, I. Y. (2016). Pemanfaatan E-commerce dan M-commerce dalam Bisnis di Kalangan 
Wirausahawan Perempuan. STIE Perbanas Press, 5(1), 237-256. https://doi.org/10.14414/jbb.v5i2.544

Imammulhadi. (2002). Penyelesaian Sengketa dalam Perdangan decara Elektronik. Jakarta: Elips.

Mahmood, S. M. F. (2016). Measuring the Impact of Internet, Technology \& Human Communication: A Study on Bangladesh. International Journal of Information and Communication Sciences, 1(2), 17-23. https://doi.org/10.11648/j.ijics.20160103.16

Makarim, E. (2000). Kompilasi Hukum Telematika. Jakarta: PT. Gravindo Persada.

Mamudji, S. S. dan S. (1995). Penelitian Hukum Normatif Suatu Tinjauan Singkat. Jakarta: Rajawali Pers.

Mancuso, S. (2007). Consumer protection in E-commerce transactions: A first comparison between European law and Islamic law. Journal of International Commercial Law and Technology, 2(1), 1-8. Retrieved from https://media.neliti.com/media/publications/28778-EN-consumerprotection-in-e-commerce-transactions-a-first-comparison-between-europe.pdf

Ngafifi, M. (2014). Kemajuan Teknologi Dan Pola Hidup Manusia Dalam Perspektif Sosial Budaya. Jurnal Pembangunan Pendidikan: Fondasi Dan Aplikasi, 2(1), 33-47. https://doi.org/10.21831/jppfa.v2i1.2616

Nogoev, A., Yazdanifard, R., Mohseni, S., Samadi, B., \& Menon, M. (2011). The Evolution and Development of E-commerce Market and E-Cash. International Conference on Measurement and Control Engineering 2nd (ICMCE 2011), 1(1), 1-5. https://doi.org/10.1115/1.859858

Romadhoni, R., \& Kharisma, D. B. (2019). Aspek Hukum Kontrak Elektronik (E-Contract) dalam Transaksi E-commerce yang Menggunakan Bitcoin Sebagai Alat Pembayaran. Jurnal Privat Law, 7(1), 49-54. Retrieved from https://jurnal.uns.ac.id/privatlaw/article/download/30098/20412

Sedarmayanti, \& Hidayat, S. (2002). Metodologi Penelitian. Bandung: Mandar Maju.

Suparni, N. (2001). Masalah Cyberspace Problematika Hukum dan Antisipasi Pengaturannya. Jakarta: Fortun Mandiri Karya.

Wibowo, E. A. (2016). Pemanfaatan Teknologi E-commerce dalam Proses Bisnis. Equilibiria, 1(1), 95108. Retrieved from http://journal.unrika.ac.id/index.php/equi/article/view/222

Yuliana, O. Y. (2000). Penggunaan Teknologi Internet dalam Bisnis. Jurnal Akuntansi Dan Keuangan, 2(1), 36-52. https://doi.org/10.9744/jak.2.1.pp.36-52 